\title{
A Risk-Based Analysis of Design Practices in Regard to Passenger Hazard Exposure in Open Mass Transit Stations
}

\author{
Sebastian Gintschel $^{1,2} \cdot$ Phumin Kirawanich $^{2,3}$ (D
}

Received: 19 June 2019/Revised: 13 November 2019/Accepted: 3 December 2019/Published online: 6 January 2020

(C) The Author(s) 2020

\begin{abstract}
Design practices in regard to passenger hazard exposure in mass transit stations that are directly open to the atmosphere, so-called open stations, are the focus of this study. The benchmarking exercise intends to provide a comprehensive review regarding the application of existing international and national design codes, standards, and guidelines in terms of their ability to mitigate hazards at key points of contact (POC) between passengers and station, such as walking surfaces, stairs, lifts, escalators, and wayfinding, during normal and emergency conditions. By adopting the safety-related risk assessment model, the benchmarking exercise uses national Thai station design practices as a baseline in order to identify applicable national codes, standards, and guidelines, and to conduct a parallel comparative analysis with respect to their international counterparts in order to identify, rank, and evaluate the potential impacts of missing regulations and practices. The analysis shows that a number of station environment-related risks appear along the different paths of egress and at different POC that must be addressed. With the application of Thai national codes, standards, and guidelines alone, the designer is still susceptible to design
\end{abstract}

Phumin Kirawanich

phumin.kir@mahidol.ac.th

Sebastian Gintschel

sebastian.gintschel@wsp.com

1 WSP (Thailand) and WSP Global Inc., Bangkok, Thailand

2 The Cluster of Logistics and Rail Engineering, Mahidol University, Nakhon Pathom, Thailand

3 Electrical Engineering Department, Mahidol University, Nakhon Pathom, Thailand

Communicated by Marin Marinov. decisions that do not reduce risk levels. It was also found that more than half of the risks in paths of egress remain undesirable or intolerable after the design, and thus pose a threat of injury to passengers and create growing concerns for operators. Based on the findings of the study, a recommendation can be made for the use of a design handbook for stations by ranking different existing standards in accordance with their importance to the design endeavor, with legal support from involved parties.

Keywords Station design standards · Passenger hazards in station - Station design practice $\cdot$ Station safety $\cdot$ Passenger safety $\cdot$ Risk analysis

\section{Introduction}

Following political turmoil from 1998 to 2003, the Thai public was concerned that private-sector entities such as large-scale real estate developers might be able to obtain commercial rights over public land. Thus, the government passed successive resolutions to ensure that the public may enter into an agreement with a private party only if the sole rights to the property remain with the government. The selected approach was similar to that outlined in the International Federation of Consulting Engineers Red Book [1], which calls for construction in accordance with an "owner's design" scheme for civil and building engineering works.

Under this scheme, all permanent structures are designed by a design consultant in accordance with codes and design experiences based on regular public buildings, whereas no specific codes for the design of mass transit stations are appropriately enforced. The structures constructed under this scheme are carried over as-is to the 
railway systems project implementation or concessions, which are managed by the respective authorities under the jurisdiction of the Office of Transport and Traffic Policy and Planning (OTP). This is demonstrated by the diagram in Fig. 1.

In the best international practice, the System Engineering Handbook [2] has typically outlined a model with identification of requirements, which is then successively implemented in design-build projects that should be considered as the traditional way to build systems.

Focusing on the processes prior to the design practice, it is imperative that all requirements, including codes, standards, and guidelines, be correctly and completely identified before commencing the design. Where such suitable prerequisites do not exist, international and other national requirements shall be applied. Where there are requirements in place that negatively affect system safety, these requirements shall be worked out before or even during design execution.

This is an issue for Thai designers, as the common perception of the hierarchy of requirements includes project directives given by the government agency steering committee, applicable laws and regulations consistent with the Thai building code for public buildings [3], and the designer's organizational policies and procedures, which are influenced by the capacity to deliver the design project

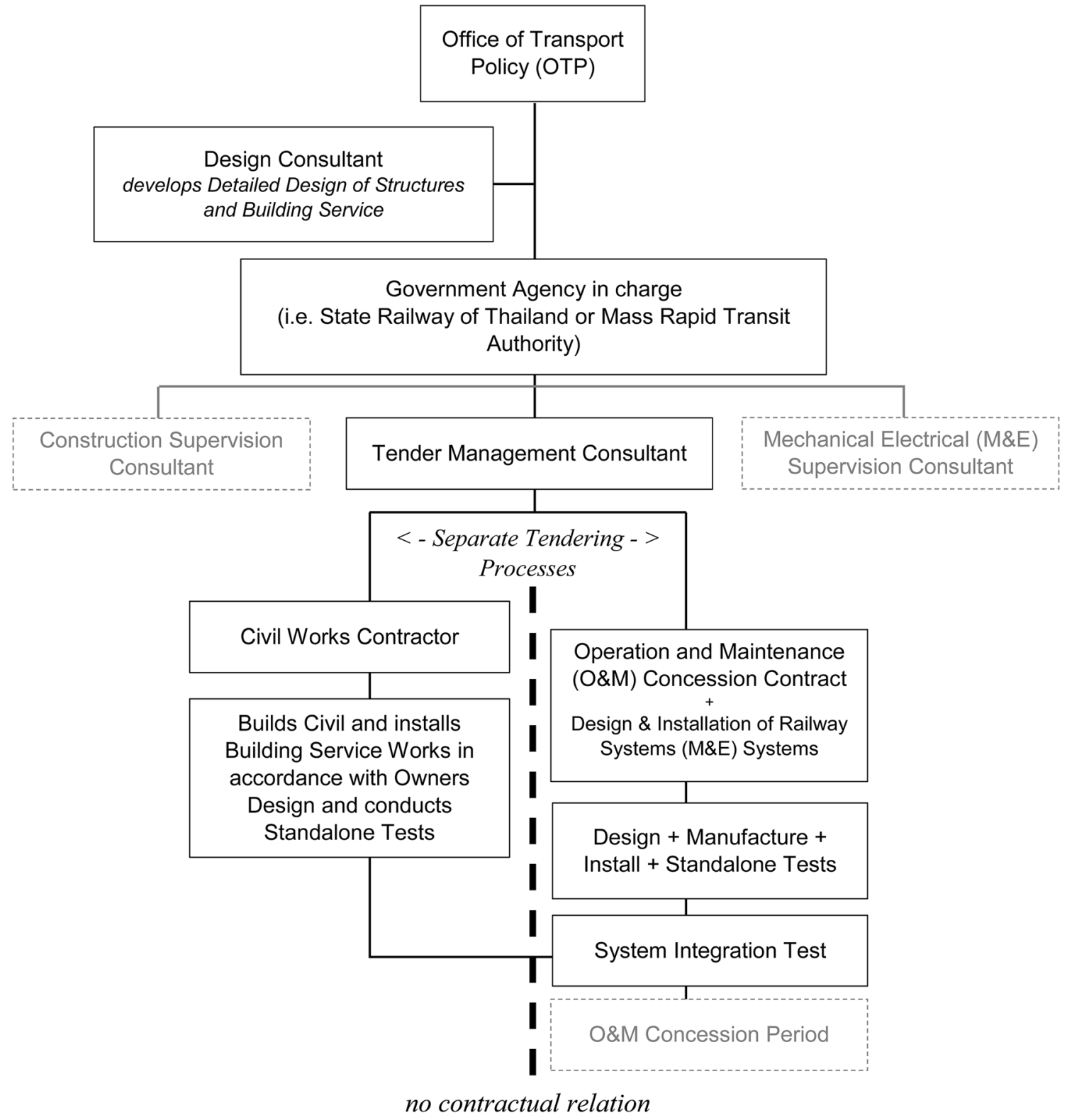

Fig. 1 Owner's design scheme for civil and building engineering works demonstrating no relationship between the mass transit station construction design and railway systems implementation by an O\&M concessionaire 
on time and within a consultancy budget. The last consideration is usually the industry standard, which is not legally enforced in Thailand.

Thus, without independent review by railway system suppliers, certification consultants, or railway operators that have not yet been engaged, issues remain open for resolution at the time of station construction. One particular issue is the lack of sufficient legal requirements for identifying, mitigating, and documenting the reduction of risk to an acceptable level in accordance with the International Electrotechnical Commission's (IEC) standard for railway applications specification and demonstration of reliability, availability, maintainability, and safety (RAMS), or IEC 62278 [4]. Legal requirements are similarly lacking for applying evacuation calculations in accordance with National Fire Protection Agency (NFPA) standards for fixed guideway transit and rail passenger services or NFPA 130 [5], station design criteria in accordance with the Life Safety Code or NFPA 101 [6], or other comparable standards. This causes higher than normal passenger exposure to hazards in the fixed structures and minor but sometimes also major accidents if no substantial investment is made to reduce these risks.

Thus, in order to clearly show that following regular Thai building design practices is not sufficient to control risks to passengers, this study is to expose the deficiency in Thai building standards when applied to the design of a mass transit station.

\section{Methodology}

In order to provide a systematic approach and to avoid comparing prescriptive design codes or standards that follow different philosophies from those of Thai codes or guidelines as mentioned above, a more precise approach is needed. While numerous studies have used safety-related risk assessment models for railway systems to evaluate the consequences of accidents by considering the influence of component defects such as tracks [7], rolling stocks [8], road-rail level crossings, [9] and train control systems [10], none has reported the application of such an approach to achieve risk reduction for mass transit station facilities that would directly impact passengers.

The approach proposed in this study is enabled by applying a risk-based analysis in accordance with IEC 62278 [4] and recording Thai design practices as risk mitigation processes. Basically, conventional risk assessment methods require extensive efforts to carefully walk through all of the station standards until the risks were revealed. Instead, a bottom-up approach is proposed in this work by first evaluating the risks based on their worst-case outcome for passengers until the causes in design are exposed. In parallel, the study will compare the content and extent of the Thai standards with a control sample of internationally recognized codes, standards, or guidelines to provide a benchmark against industry best practice. The aim of the study is therefore to highlight differences and conflicts between standards, shortcomings in terms of hazards which are not addressed through the application of either national or even international standards, and potential consequences in terms of passenger exposure to hazards and subsequent risks. The study also provides initial evidence that general attempts to comply with a variety of codes or standards can potentially create confusion and ultimately result in reduced passenger safety in the design.

The results will identify the gaps and relevant need for changes in processes to incorporate railway application requirements into the design practices of the owner's design and subsequent construction of the stations to reduce or eliminate hazards.

\subsection{Focus and Framework of Study}

In sequence, passengers using the services of the system would typically (1) enter a station at the landing, (2) use the stairs, escalator, or elevator to gain access to the concourse unpaid area, (3) purchase a ticket at either the ticket vending machine or the ticket counter, (4) validate the ticket at the gate line, (5) proceed to the platform level via stairs, (6) gather at the platform, and (7) successively board the train. After reaching their destination, passengers would then de-board the train and successively undergo the same steps in reverse order except for the ticket purchase.

This comparative study focuses on the different design and engineering requirements for points of contact (POC) between passengers and stations that may be considered hazards, including walking surfaces, stairs, lifts, escalators, and wayfinding required during normal and emergency conditions, as shown in Fig. 2. As the train is already designed and constructed strictly in accordance with international standards, it is presumed to not contribute to this study, and is thus excluded.

\subsection{Risk Management}

As discussed above, analyzing the passenger POC and possible associated risks would thus result in a comprehensive risk matrix for normal operations. For emergency operations, a similar approach could be used, with the exception that all steps would be in reverse order, i.e., as passengers are escaping, and including considerations of crowd dynamics and fire. 
Fig. 2 Framework of study focusing the points of contact between passengers and stations open to the atmosphere, including walking surfaces, stairs, lifts, escalators, and wayfinding required during normal and emergency conditions

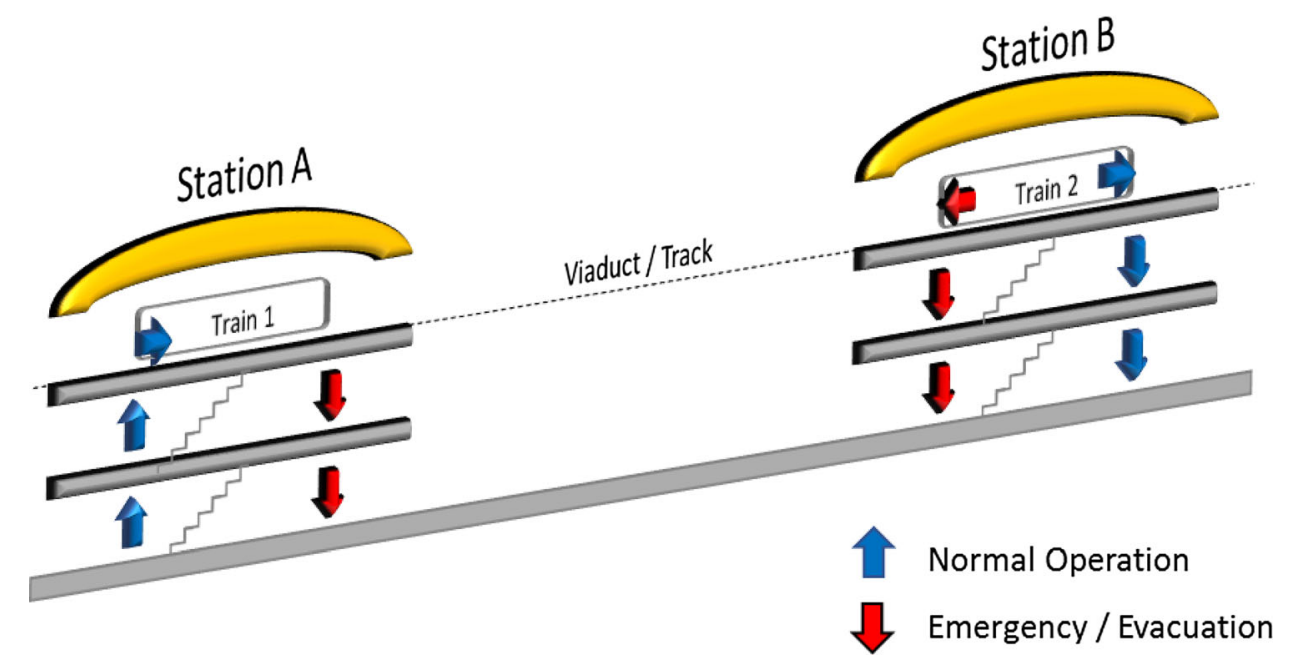

\section{a. Identification of Risks}

The identified passenger contact points can be considered the hazards to which the passenger is exposed during boarding and alighting. An analysis of the passenger's exposure to the station's POC must be conducted against risks that could be found in any infrastructure as indicated in Table 1 [11]. These predefined risks can be allocated to the passenger POC-related hazards with a relevant description to understand their context in regard to risk occurrence based on the nature of the passenger's exposure to situations in normal and emergency operations.

\section{b. Identification of Worst-Case Result}

When this is established, the next task is to identify the possible worst-case result of this risk to the passenger(s) and rank it in accordance with the severity of the result, from highest to lowest, as follows: (1) multiple fatalities, (2) single fatality, (3) multiple severe injuries, (4) minor injuries, and to (5) simple injuries (cuts and bruises).

\section{c. Identification of Risk Level}

Standard IEC 62278 [4] categorizes risk in accordance with a predefined risk level on the basis of frequency determinants and levels of consequences, as laid out in Table 2. These risk levels are established based on the combined severity and frequency of the risk, as shown in the risk matrix in Table 3. Once the overall ranking or relevance of the risk is established, the importance of ranked risks can be categorized and will impact the operational expenses as first aid where the treatments will cause operational effort and preparedness.

\section{d. Mitigation through Design Practice}

The mitigation measures relevant to station engineering design practice in Thailand can be categorized based on the

Table 1 Relevant risk exposures in this study

\begin{tabular}{ll}
\hline Risk & Description \\
\hline Panic & Panic is the occurrence of uncontrollable fear or anxiety in passengers, possibly causing wildly unthinking behavior \\
Stampede & Stampede is the sudden rapid movement or reaction of a mass of people in response to a particular circumstance or stimulus \\
Asphyxiation & Asphyxiation is the state or process of being deprived of oxygen, which can result in unconsciousness or death by suffocation \\
Entrapment & Entrapment is the state of being caught in a room or location without a self-determined ability to escape \\
Electrocution & Electrocution is injury or fatality by electric shock \\
Slip & Slip is the loss of footing resulting in a fall, usually backwards, due to insufficient friction with the walking surface \\
Trip & Trip is the of loss of footing due to an object impeding the foot's movement, resulting in a fall, usually forward \\
Fall & Fall is the loss of footing due to an unexpected level change \\
Impact & Impact is the impact of an object with a person or the person's impact on the object \\
Pinching & Pinching is the action of getting caught in moving elements of a machine or object \\
\hline
\end{tabular}


Table 2 Risk level defined in accordance with EN 50126/IEC 52278

\begin{tabular}{ll}
\hline Risk level & Hazard reduction/control \\
\hline Intolerable & Not acceptable. Hazard shall be eliminated \\
Undesirable & Shall only be accepted when risk reduction is impracticable and with the agreement of the operator/owner \\
Tolerable & Acceptable with adequate and approved control measures \\
Negligible & Can be accepted without any further action
\end{tabular}

Table 3 Risk matrix

\begin{tabular}{ccccc}
\hline Frequency of Occurrence & \multicolumn{4}{c}{ Risk Levels } \\
& Undesirable & Intolerable & Intolerable & Intolerable \\
Probable & Tolerable & Undesirable & Intolerable & Intolerable \\
Occasional & Tolerable & Undesirable & Undesirable & Intolerable \\
Remote & Negligible & Tolerable & Undesirable & Undesirable \\
Improbable & Negligible & Negligible & Tolerable & Tolerable \\
Incredible & Negligible & Negligible & Negligible & Negligible \\
\hline & Insignificant & Marginal & Critical & Catastrophic \\
& & Severity Levels & \\
\cline { 2 - 5 } & & &
\end{tabular}

requirements imposed by the designs, which include project directives, terms of requirements given by the government agency, the steering committee, applicable laws and regulations generally consistent with the Thai structural and building codes or guidelines, and the designer's organizational policies and procedures, which are influenced by the capacity to deliver the design project on time and within budget.

In this study, a comparison between Thai and international design practice, in accordance with requirements outlined in codes, standards, and guidelines such as IEC, EN, and NFPA or directives by relevant national safety agencies, is also demonstrated in the form of a second column populated with applicable mitigation practices in international practice.

Assuming that the risk mitigation processes in the relevant Thai design requirements (directives, codes, standards, and guidelines) are fully implemented, the risk is to be reevaluated in terms of reduced risk frequency and severity, resulting in a (new) subsequent risk level. From this we can identify whether the risk has been reduced to an acceptable level by applying the Thai design requirements alone. We can then also draw parallels to international design requirements listed against the same risks and discuss the difference in effectiveness.

\section{e. Flow of Study}

The flow of study relevant to the items as discussed above can be explained by the diagram in Fig. 3. The process starts with identifying the worst-case outcome to passengers. After the selection of operational conditions and the paths of egress, i.e., traveling between station levels, on concourse, and on platform, the POC are determined, including the selection of possible related risks, for discussion. Finally, the deficiency of building standards for a mass transit station design is revealed following the benchmarking between Thai and international requirements.

\section{Results, Analysis, and Discussion}

In this paper, risk assessment was conducted for the case study of the application of design standards to mass transit station design in Thailand. Using the risk severity, frequency, and resulting risk level as defined in IEC 62278 [4], a comprehensive study and evaluation of passenger risk exposure was performed. The individual national and international design practices were allocated as mitigation strategies in the design, and the study produced many interesting results. Tables 4,5 , and 6 detail findings regarding slip, trip, and fall risks to passengers in the paths of egress in contact with landing and intermediate landing, stairs, and pathways.

From the assessment results as listed, both national and international design practices have requirements that means of egress, specifically stairs, "shall be continuously maintained free of all obstructions or impediments to full instant use in the case of fire or other emergency" (NFPA 101, p. 101-54) to highlight the importance of free egress. 
The NFPA Life Safety Code, otherwise known as NFPA 101 [6], and the Thai building codes [3] and other norms all require slip-resistant surfaces for fire escape stairs, with certain stair riser and tread depths which are different across Thai codes and guidelines. Furthermore, Thai codes and guidelines lack requirements for stair nose dimensions and requirements in regard to slip resistance of floor material on the POC with the station along the concourse, platform, and stairs. In addition, there are no known codes, standards, and guidelines in Thailand that provide quantitative measures or material test procedures to assess slip resistance for floor materials. The international best practice control sample, given in the form of NFPA 101, provides specific details implying that the designer is to consider "foreseeable slip conditions are those that are likely to be present at the location of the walking surface during the use of the building or area" (NFPA 101, p. 101-408) and further indicating required compliance with material standards in accordance with the American Society for Testing and Materials standard (ASTM F1673) concerning the practice for safe walking surfaces [12].
Thai design codes, guides, and standards are silent concerning requirements to measure material slip resistance for both indoor and outdoor, and Thai designers openly apply materials such as polished granite for the flooring of walking surfaces and means of egress in the stations. This is largely justified with the argument that materials such as polished granite have superior esthetics and ability to be cleaned. As a further comparison to the UK Health and Safety Executive's study of the slip characteristics of natural and man-made stone flooring materials [13], it specifically identifies polished granite as a material with high slip potential, apparently to dissuade designers from using it in public areas.

In addition to slip resistance, the in-depth study of Thai design requirements revealed that the ministerial regulation for the arrangement and facilitation in building or vehicles and logistics for handicapped lacked clarity in terms of which stairs would be required to be stairs for persons with reduced mobility [14]. Thus, it is possible to misinterpret that stair dimensions for persons with reduced mobility apply to all stairs of the station, resulting in lower stair

Fig. 3 Risk assessment and benchmarking methodology for passenger hazard exposure in open mass transit stations

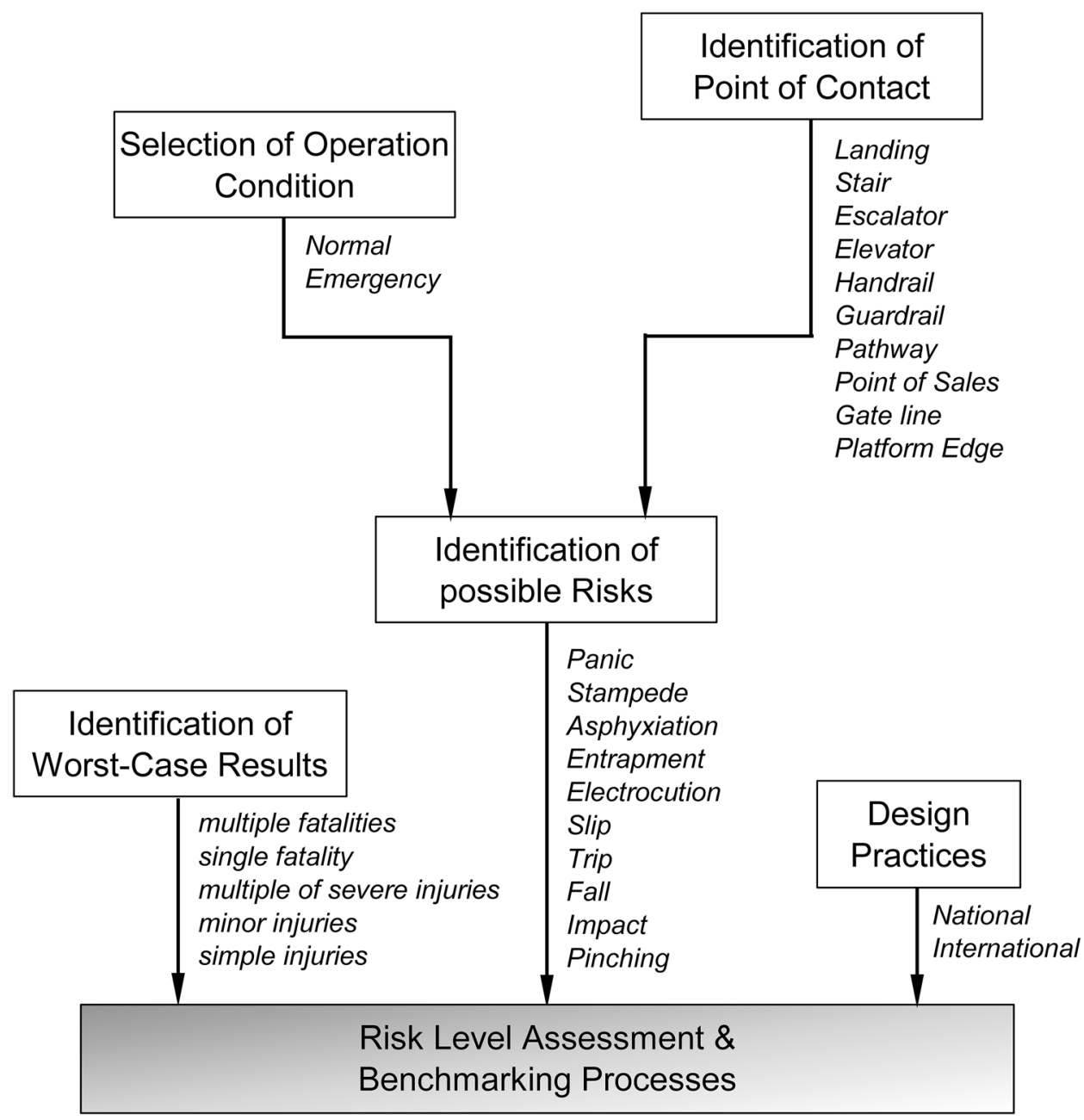




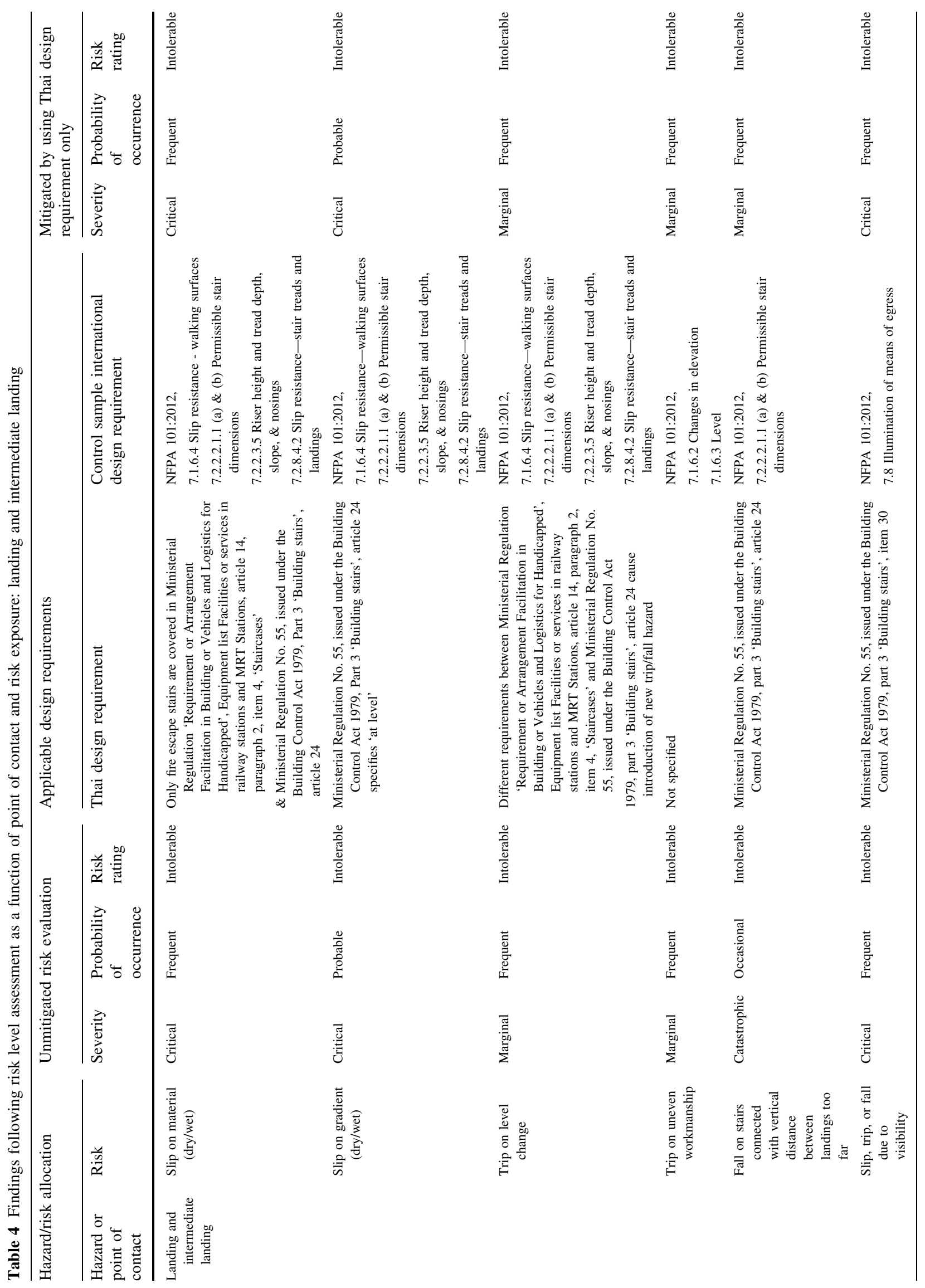




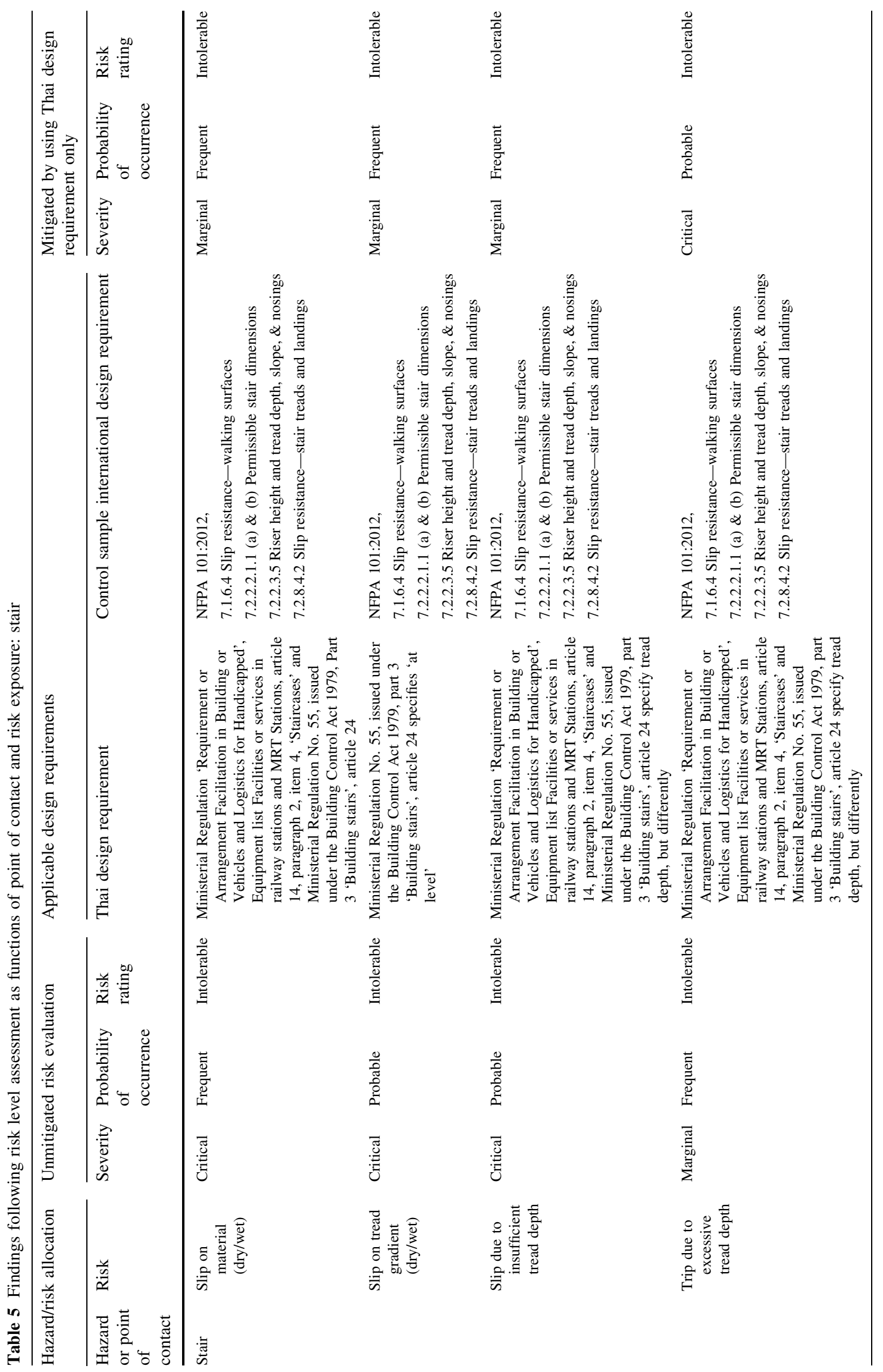




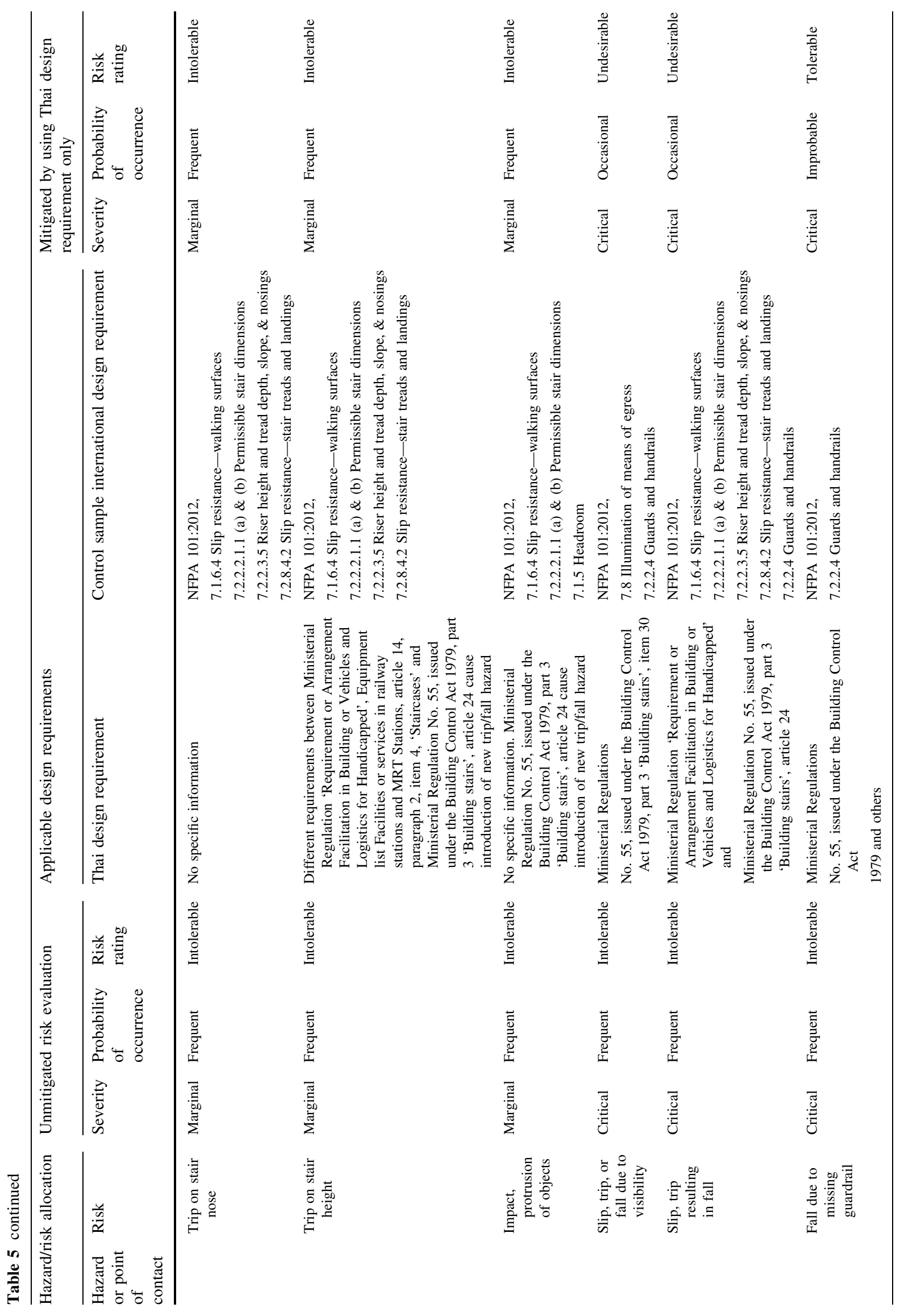




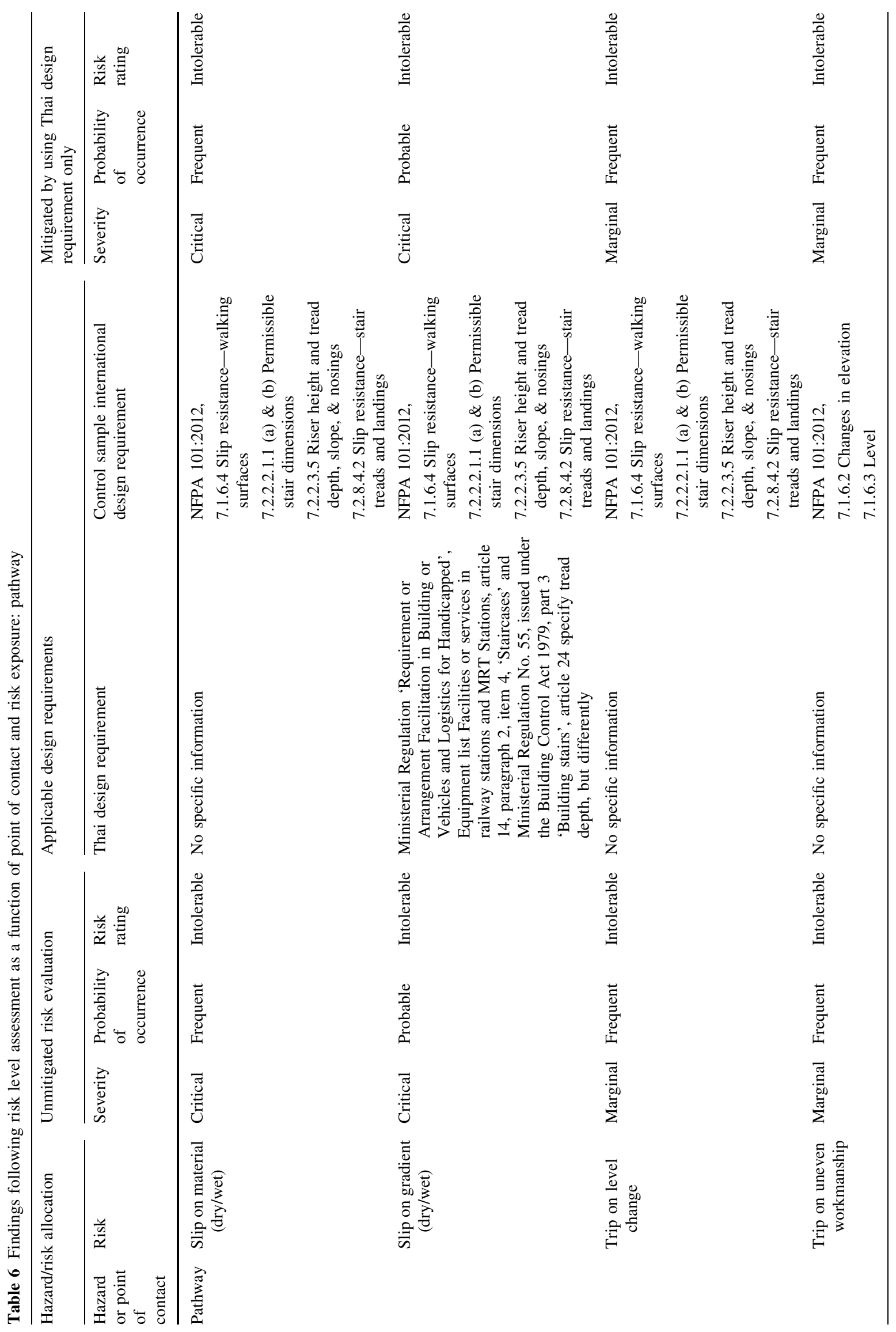




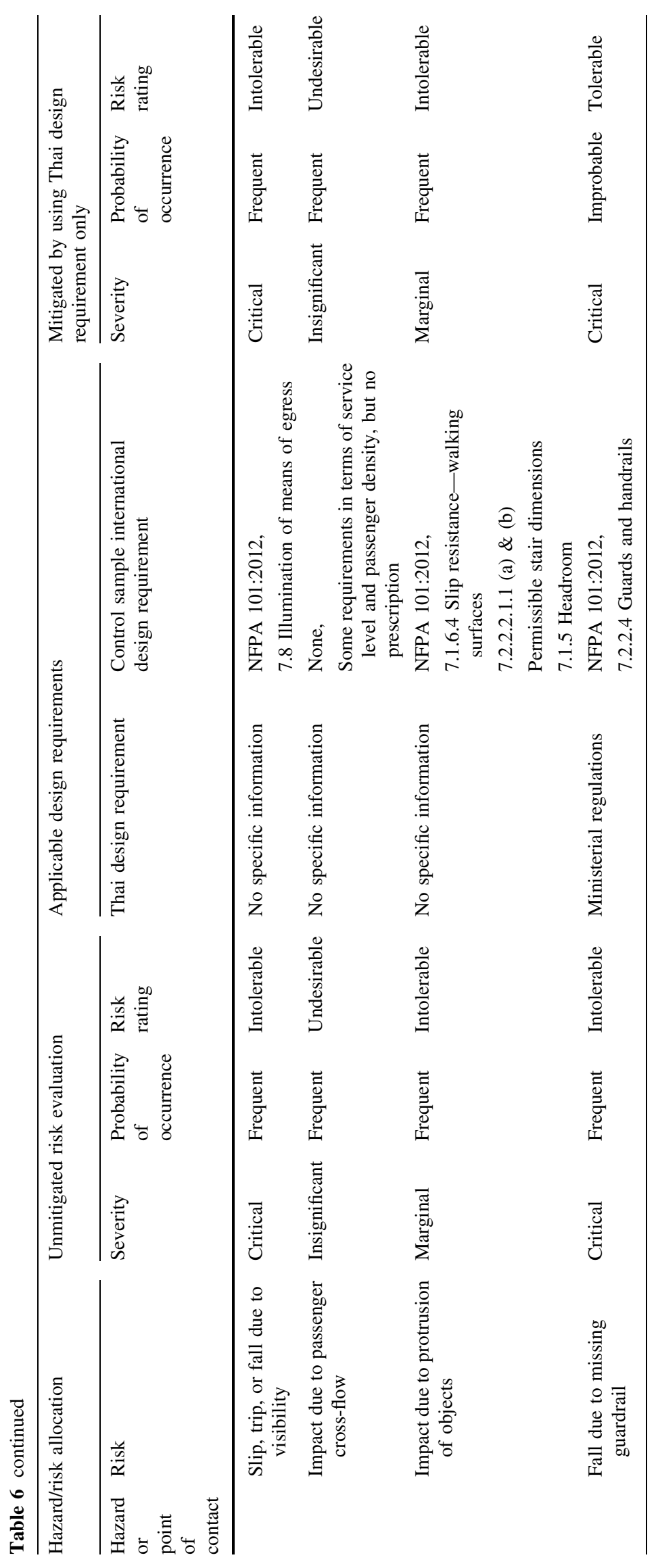


risers and longer stair steps in these staircases. It shall be further investigated whether these different stair dimensions result in the creation of an additional fall risk due to unexpected changes in stepping distance across different stations of the same system or interchanges between different systems designed in accordance with different codes.

\section{Conclusions}

In this paper, a risk assessment was conducted for each POC between passengers and the open mass transit station for boarding and alighting. The results show that in three distinct paths of egress through stairs, lifts, and escalators, as well as walking surfaces on concourse and platform areas, a total of 190 risks at about 22 POC can occur, some of which have been selected for discussion here. With the sole application of Thai national codes, standards, and guidelines, the designer is highly susceptible to making decisions based on insufficient requirements, compared with the more established requirements of the international standards provided in the international best practice control sample, as demonstrated in Tables 4, 5, and 6 .

As the study already indicated, there are many discrepancies between the standards, resulting in differences of opinion and different interpretations between the station designers. Interestingly, this is not a new problem, and many state operators are aware of these problems in their infrastructure design. One example to demonstrate misinterpretation between standards is the finding from a recent project where the design requirements envisaged compliance with the design code for the arrangement facilitation in building or vehicles and logistics for handicapped [14], but neglected other standards in the design of handrails at the stair POC, which are used to reduce the likelihood and severity of falls. This results in having handrails unacceptably higher than normal on two out of four stairs in the station, as shown in Fig. 4. This was most likely the result of following only the design code mentioned above that requires so-called low handrails but fails to detail how these are measured, i.e., height of handrail from the tread nosing line or the top of stair riser as fully specified in other standards. Besides failing to provide appropriate measures to mitigate passenger fall risk, it would cause an additional investment for retrofitting of lower handrails.

Since international codes, standards, and guidelines are not legally enforced in Thailand (though in rare conditions they are required by the government agency steering committee), compliance with these requirements is not legally enforceable. In contrast, Thai national guidelines, applicable or not, are drafted by the Engineering Institute of Thailand (EIT) and are binding for the EIT-licensed Thai engineers and architects. Some guidelines are also later codified as

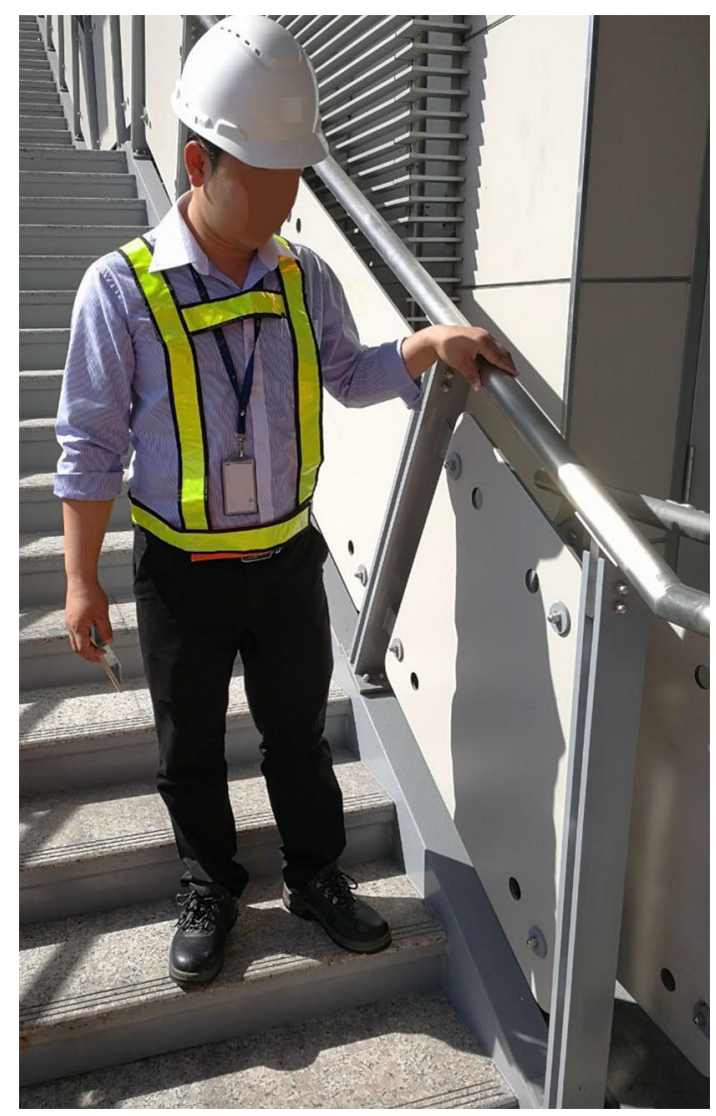

Fig. 4 Design and construction of handrails at a height of $1220 \mathrm{~mm}$ with $50-\mathrm{mm}$ tubing due to misinterpretation of design standards, posing a hazard and increasing risks to children and the elderly

design codes in the form of ministerial regulations, which makes them a legal baseline for the design. A good example would be the legal use of the Ministerial Regulation No. 55 [15], which is a re-issuance of the content first published as the Bangkok building codes [3]. Thus, these codes become legally binding in Thailand.

This study has shown that risks in paths of egress remain undesirable or intolerable when Thai national codes, standards, and guidelines alone are followed. There is no unified approach to standards in the construction of civil, architectural, and building service works that explicitly mitigates risk to passengers and the public through design. In addition, the designer's legal responsibility to provide evidence that the risks in the design have been kept to a level as low as reasonably practicable (ALARP) in accordance with IEC 62278 [4] would be expected from all designs on a railway system.

Thus, the resulting designs lack common design requirements that harmonize the stations between designers, and result in a worrying prospect concerning risk exposure among Thai passengers and the public. 


\section{Future Work}

Many state operators have resolved these issues by creating a design handbook for stations, such as the Manual for Standards and Specification for Railway Stations [16]. This manual combines the different standards in existence and ranks them in accordance with their importance to the design endeavor. It also governs how the different standards are to be interpreted for the station design works.

Applying this to Thailand in the future, however, will not be an easy task. Thailand has three major government agencies overlooking the design of stations, namely the Bangkok Metropolitan Authority, the Mass Transit Authority of Thailand, and the State Railway of Thailand. In addition to these agencies that would have to cooperate and buy into this idea, the support of the Engineering Institute of Thailand and the Association of Siamese Architects would also have to support the idea in order for their members to legally utilize this design handbook.

\section{Compliance with Ethical Standards}

Conflict of interest The authors declare that they have no conflict of interest.

Open Access This article is distributed under the terms of the Creative Commons Attribution 4.0 International License (http://crea tivecommons.org/licenses/by/4.0/), which permits unrestricted use, distribution, and reproduction in any medium, provided you give appropriate credit to the original author(s) and the source, provide a link to the Creative Commons license, and indicate if changes were made.

\section{References}

1. International Federation of Consulting Engineers (FIDIC) (1999) FIDIC red book: conditions of contract for construction for building and engineering works designed by the employer, Switzerland

2. Aslaksen E, DeLamare M, Fehon K, Godau R, Knott A, Kouassi A, Liefde J (2013) Guide for the application of systems engineering in large infrastructure projects. International Council on Systems Engineering (INCOSE)

3. Bangkok Metropolitan Authority (2544) Building Code for Public Buildings, Engineering Institute of Thailand (EIT), TH

4. International Electrotechnical Commission - IEC 62278 (2002) Railway applications-The specification and demonstration of reliability, availability, maintainability and safety (RAMS)

5. National Fire Protection Agency - NFPA 130 (2017) Standard for fixed guideway transit and rail passenger services

6. National Fire Protection Agency - NFPA 101 (2018) Life safety code

7. Cafiso S, Graziano AD, Blasi ND (2006) Risk assessment on railway transportation of hazardous materials. WIT Trans Ecol Environ 91:97-106

8. Dinmohammadi F, Alkal B, Shafiee M, Berenguer C, Labib A (2016) Risk evaluation of railway rolling stock failures using FMECA technique: a case study of passenger door system. Urban Rail Transit 2(3-4):128-145

9. Berrado A, El-Koursi EM, Cherkaoui A, Khaddour M (2011) A framework for risk management in railway sector: application to road-rail level crossings. Open Transp J 5:34-44

10. Jo HJ, Hwang JG, Kim YK (2007) Risk assessment method for guaranteeing safety in the train control system. WIT Trans Built Environ 96:567-576

11. Occupational Safety and Health Administration - OSHA 29 CFR 1910 (1999) Occupational safety and health standards

12. American Society for Testing and Materials - ASTM F 1673 (2013) Standard practice for safe walking surfaces

13. Morrey ML (2007) A study of the slip characteristics of natural and manmade stone flooring materials. Research Report 529, Health and Safety Executive (HSE)

14. Ministry of Transport (2013) Arrangement facilitation in building or vehicles and logistics for handicapped

15. Ministerial Regulation No. 55 (2000) Issued pursuant to the Building Control Act, 1979

16. Ministry of Railways (Railway Board) (2009) Manual for standards and specifications for railway stations, vol 1, India 